Available online at www.eccomasproceedia.org

Eccomas Proceedia COMPDYN (2021) 1170-1187

ECCOMAS

Proceedia
COMPDYN 2021

$8^{\text {th }}$ ECCOMAS Thematic Conference on Computational Methods in Structural Dynamics and Earthquake Engineering M. Papadrakakis, M. Fragiadakis (eds.) Streamed from Athens, Greece, 28 - 30 June 2021

\title{
CORRELATION OF VULNERABILITY AND CONSERVATION BETWEEN ARTISTIC ASSETS AND STRUCTURAL ELEMENTS: CAMPAIGN OF THERMOGRAPHIC SURVEYS ON THE FRESCOES OF THE TEMPLAR CHURCH OF SAN BEVIGNATE
}

\author{
R. Liberotti, F. Cluni, F. Faralli and V. Gusella \\ Department of Civil and Environmental Engineering \\ University of Perugia 06125 Perugia, Italy \\ e-mail: \{riccardo.liberotti, francesco.faralli\}@studenti.unipg.it \\ e-mail: \{federico.cluni, vittorio.gusella\}@unipg.it
}

\begin{abstract}
A museum, an art collection and a heritage architecture all in one the former Church of San Bevignate is a 39.5m long masonry building that overlooks the countryside of the Umbria Region in Italy. Part of a Templar complex of the 13th century located in Perugia, it holds within a precious series of frescoes, depicting the heroic deeds of the temple's knights across crossings and borders. The safeguard of historical buildings in seismic hazard-prone Regions, as in this case, needs specific measures due, amongst other reasons, to the presence of artistic assets unmovable precisely as frescoes, valuable plasters/stuccoes or in general wall decorations. Therefore, to define a correlation of the seismic risks between masonry structural systems and artworks is a mandatory condition in order to perform safety evaluation and to identify the proper conditions for possible interventions. The efforts made to increase the level of knowledge concerning such buildings mainly through Non-Destructive Testing (NDT) are also important for such purposes. In this context, a non-invasive and contactless method was devised, which integrates the use of the thermal imaging camera with post-processing techniques and calculation algorithms, aimed at revealing the peculiarities inherent in the walls decorated with frescoes: a little-known possibility to bring out important factors for the conservation of the frescoes and also information on the seismic vulnerability of such historical masonry architectures in order to preserve the artefact from being damaged.
\end{abstract}

Keywords: Heritage, NDT surveys, Museum collections, Thermography, Masonry.

ISSN:2623-3347 @ 2021 The Authors. Published by Eccomas Proceedia.

Peer-review under responsibility of the organizing committee of COMPDYN 2021.

doi: $10.7712 / 120121.8554 .19352$ 


\section{INTRODUCTION}

The protection of several types of museum collections against seismic phenomena is increasingly gaining interest among a range of stakeholders: the arts and culture sector, scientists, people working in local authorities and governments. Such approach takes into account the observation that in many cases damages to heritage buildings and art goods are irreparable and parietal art pieces e.g. frescoes, decorations and stuccos, are the example by antonomasia of such scenario. Indeed, the aftermath of the recent Italian earthquakes (L'Aquila, Amatrice etc.) in terms of destruction and harms to the historical collections and works was not secondary. Special programs of earthquake preparedness must be conducted in order to mitigate the expected hazard, especially for earthquake-prone countries, such as the Mediterranean countries and besides to avoid cultural losses that may have consequences on entire communities $[1,2,3]$. This contribution presents a contemporary approach to the theme of experimental investigations relating to the protection of heritage masonry buildings and the parietal art goods associated with it. The article constitutes the last phase of a research path started with laboratory tests $[4,5,6]$ and, with the collaboration of the Municipality of Perugia, applied subsequently to a case study of value [7] and within the present contribution is examined more closely: the Italian Templar church of San Bevignate, part of an architectural complex from the 13th century located in the city of Perugia. Especially, this heritage building was selected because pose special challenges for damage detection and conservation, due to the presence of large parts of frescoed masonry surfaces. So, this heritage building represents a museum of itself, of its values and its precious original contents. The diagnostic methodology applied in this work is the passive thermography by means of an Infra-Red (IR) thermal camera that acquires the frescoes'painted surface without the emission of artificial thermal loads to the frescoes themselves backed up by the implementation of digital imaging processes. The surveys allowed identifying the main masonry damages like fissures, damages in stone elements, putlog holes, with a peculiar focus on the masonries'quality and texture. By means the data acquired it has been possible to obtain, starting from the processing of thermographic data on the wall texture and by means of a homogenization technique, an estimate of the fundamental mechanical properties of the loadbearing structures. Indeed, an adequate knowledge of the masonries' peculiarities assumes great importance for the estimation, through homogenization techniques, of the mechanical characteristics [8] and collapse conditions [9] of the heritage buildings both in the static and dynamic field $[10,11]$. Besides, the in-situ measurement permitted to carry out an evaluation of the actual state of frescoes concerning other risks connected to their survivals like detachments, delamination or moist areas. So, without harming the wall frescoes, e.g. by taking the traditional essays or samples, valuable information were obtained concerning the frescoes conservation and at the same time the seismic safety of this historical former church, now a full-fledged museum site.

\section{THERMOGRAPHIC ANALYSIS}

An infrared camera is able to record the amount of radiated heat from a body.

The equation of Stefan-Boltzmann provides the relation between emitted radiation and surface temperature:

$$
E=\varepsilon \sigma T^{4}
$$

where $\varepsilon$ is the radiation $\left(\mathrm{W} / \mathrm{m}^{2}\right), T$ is the absolute temperature $(\mathrm{K}), \sigma$ is the Stefan-Boltzmann constant $\left(5.67 \times 10^{-8} \mathrm{Wm}^{-2} \mathrm{~K}^{-4}\right)$ and $\epsilon$ is the emissivity.

It is also necessary to introduce the relation between the wavelength of the maximum radia- 
tion intensity $\lambda(\mu \mathrm{m})$ and the temperature

$$
\lambda=\frac{b}{T}
$$

where $b$ is the Wien displacement constant $(2897 \mu \mathrm{mK})$.

The heat transfer in any material is affected by the presence of subsurface flaws or any other inconsistency in the material thermal properties. Localized energy gradients on the surface of a test object are due to the changes in the heat flow and can be measured using an infrared sensor.

For temperatures close to room temperature, the energy is in the infrared domain of the electromagnetic spectrum. In particular, the infrared radiation is the region of the electromagnetic spectrum located between visible light and microwaves, containing radiation characterized by wavelengths ranging from 0.75 to $10 \mu \mathrm{m}$.

Temperature distributions are obtained by data processing from the measured infrared radiation and then recorded in the form of isotherm plots or thermograms. The electronic sensor of the instrument acquires the value of energy stored by every single pixel and generate an image, in greyscale represented by black and white shades or in a combination of levels of false colours, of the observed object. To experiment the efficiency to evaluate, by means of thermographic images, the texture of masonry walls covered with plaster or frescoes, a research program was started $[4,5,6]$.

In particular, three masonry samples, which differed for the textures (periodic, quasi-periodic and random) were built. Using UNI solid bricks of dimensions $250 \times 120 \times 55 \mathrm{~mm}$, either used as a whole or split in two or four, the periodic texture was constructued with the running bond scheme and using bricks with the same widths and heights. For the quasi-periodic texture, bricks with different widths but equal heights were used, avoiding the correspondence of the vertical mortar joints. In the last case, a random texture, made using bricks with different widths and heights, was created. The masonry walls, before applying $10 \mathrm{~mm}$-thick plaster, are shown in Figure 1.

In that research, as well as for the present contribution, the thermographic camera model 885-2 manufactured by the Testo company has been used. This has a sensor of dimension $320 \times 240$ pixels. All the samples have been exposed to direct sunlight in order to improve the heat flux through the body.

To derive the masonry texture from thermographic images, the following procedure was proposed.

Assuming a $T_{t}$ threshold temperature, that field is converted to a binary function, which is a "black and white image" or material binary image, by

$$
b_{i}=b_{i}(x, y)= \begin{cases}0 & \text { if } T_{i} \leq T_{t} \\ 1 & \text { if } T_{i}>T_{t}\end{cases}
$$

where the value 1 (black) is associated with mortar pixels, the value 0 (white) with brick/stone pixels, and

$$
T_{i}=T_{i}(x, y) \quad x=1,2, \ldots, N \quad y=1,2, \ldots, N
$$

are the temperature data, relating to each thermographic image pixel, that can be reported as a scalar field where $N$ is the image width in pixels (it is assumed that the image has equal width and height). 


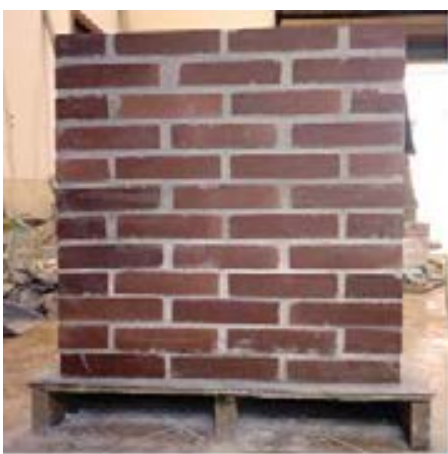

(a)

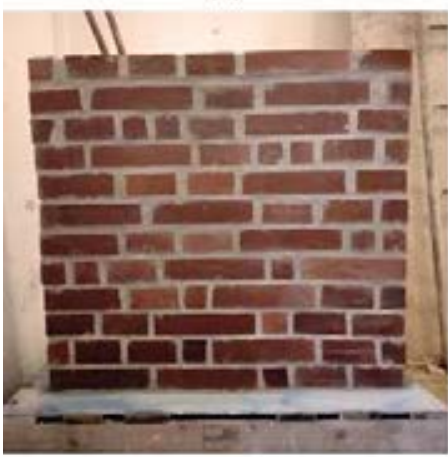

(b)

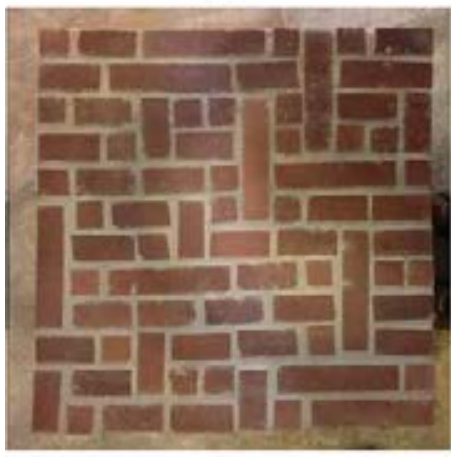

(c)

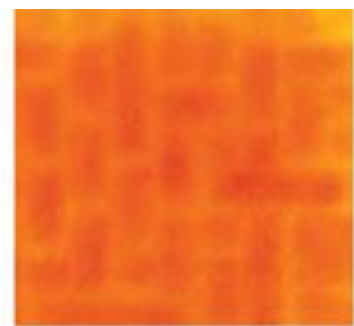

(d)

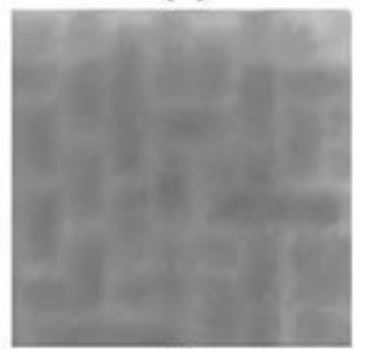

(e)

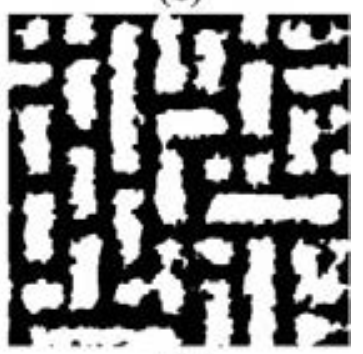

(f)

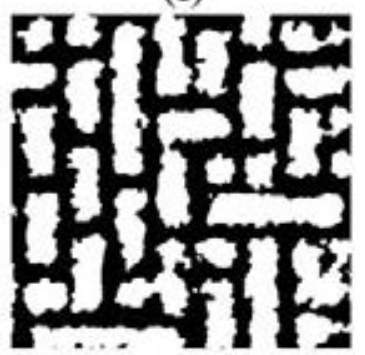

(g)

Figure 1: Samples with different masonry texture: (a) periodic, (b) quasi-periodic and (c) random. In the right column identified texture on random masonry sample: (d) thermographic image, (e) surface temperature as greyscale values $T_{i}(x, y)$, (f) black and white image after thresholding $b_{i}(x, y),(\mathbf{g})$ identified texture after the application of erosion and dilation factors, $b_{d}(x, y)$.

However, the final obtained binary image requires specific treatments in order to improve its quality. At first, mortar (black) region of pixels which are surrounded by bricks'pixels (white) are removed. Then the usage of morphological operators is required. In particular, erosion and dilation operator, in this sequence, must be used, in order to smooth the contour of the inclusions which otherwise would be very fragmented, due to the noise which belongs to the image acquisition phase.

Moreover, it was highlighted that the use of sampling Kantorovich algorithm allows to enhance remarkably the quality of the thermographic images. Furthermore, a sensitivity analysis was performed considering two sources of uncertainties: the first tied to the parameters of the morphological operator, the second related to the effects of the environmental conditions highlighting the robustness of the proposed procedure. 
Applying the described process, the outcomes shown in Figure 1 were obtained; the comparison with a digital image highlights the robustness of the procedure. In fact, the resultant black and white image has a consistent separation of phases, i.e. each stone is surrounded by mortar joints and unrealistic conjunction of inclusions is obliterated as much as possible.

Nevertheless, these results were obtained in laboratory. In order to check the reliability of the proposed procedure on real cases and underline the effective importance of this tool in the historical buildings'analysis, a peculiar study on the Templar architecture of San Bevignate has been started, a former church from the 13th century, whose internal masonry walls are almost entirely covered with precious frescoes.

\section{THE TEMPLAR ARCHITECTURAL COMPLEX OF SAN BEVIGNATE}

\subsection{History of the Church}

In the countryside of the city of Perugia, and more precisely near the monumental cemetery of Monteluce, stands out for archaeological and architectural relevance the Heritage Templar asset of San Bevignate. The church, sober and austere in its external appearance with stone facades (Figure 2), is marked inside by decorations and in particular the pictorial cycles made to remind the inhabitants of the mission carried out in the Holy Ground by the Militia Templi, a.k.a. the Templars, the religious-chivalric order created in Jerusalem around 1119 on the initiative of the French knight Hugues de Payns. This exceptional artefact testifies the presence of the order in Perugia, indeed in 1256 the city's Municipality granted the authorization at the Templar diplomat friar Bonvicino to erect the religious building in place of a small church dedicated to San Girolamo. Even though the Templars, at the time, were already present in the Umbria region at the abbey of San Giustino d'Arna, since such seat was decentralized with respect to the prosperous Perugia they requested a new one For the inhabitants of Perugia - and for the Templars - devoting the church to the figure of San Bevignate, whose history is still shrouded in mystery to this day, was important considering the popularity of its local cult back then [12]. Actually, he was not proclaimed a saint by the church of Rome but it was "laically" canonized only in 1453 by means of a decree of the Municipality of Perugia. The Templars could not see the cult of San Bevignate approved as the Congregation of Rites approved the Sanctification only in 1605 , despite this they considered him already the first Templars'Saint.

In 1262 the building of the Church was finished and also that of the Romanesque bell tower with square plan. The construction of the former monastery - now used as a private residence is coeval to the one of the octagonal well, still visible in the garden to present day. In 1312, with the suppression of the Templar Order, the monastery passed to the knights of San Giovanni of Jerusalem and in 1324 Ricco di Corbolo, a merchant of Perugia, bought the architectural complex and established a female monastic community there, likewise placed under the rule of the Order of San Giovanni. In 1517, due to economic problems, the nuns who had dwelt there were forced to leave the monastery which returned to the fully possession of the Order of San Giovanni [13]. Since then, the church gradually lost its importance and in 1860, with the suppression of various religious bodies, became the property of the Municipality of Perugia and was deconsecrated. In the last century had various uses, a wood storage, a kennel and even a fire station and such peculiar events permitted to preserve - strikingly - the frescoes because they have been covered by plaster for decades. After a long and rather complex plan of consolidation and restoration in response to the 1997 earthquake, in 2009 the monumental site reopened to the public and the original decorative apparatus have also secured; result of an agreement between the municipality and the superintendence of fine arts of Perugia. In addition, in 2020 another 
restoration plan concerning the frescoes of the counter-façade and part of the side walls was also performed, with particular attention to the original tones to the valuable paintings.

\subsection{Architectural feature of the Church}

The church of San Bevignate is located near the ancient route Spargente that was one of the five royal access road axis to Perugia. Such a distinguished monument of Gothic architecture appears as a architecture of considerable size made of sandstone and with a double sloping facade decorated with a oculus and a single round-arched portal, adorned with a marble frame with symbols typical of the Templars, while another small entrance door crowned with an ogive arch is observable on a side. At the extremity of the façade two mighty buttresses are clearly visible and recall the others located on the perimeter walls. The building ends with a quadrangular apse interrupted by a mullioned window made in travertine. The interior of the single-nave church is divided by two large spans with an ogival cross-vaulted roof and a ribbed cruise that covers the apsidal area, raised above the level of the nave. It is one of the most important documented Templar church in the world, since there is no such cycle of frescoes not even in the Chapelle des templiers de Cressac, a Templar chapel located in southwestern France that shows a valuable cycle of frescoes of reference on this theme. In addition, it is important to stress that the presence in the church of the thirteenth-century frescoes constitute the first iconographic documentation of the motion of the flagellants, also known as the disciplined, founded in Perugia in 1260 by the friar Raniero Fasani. In this same year Bonvicino became interested in the Roman Curia, under the Pope Alessandro IV, for the canonization of San Bevignate, and thus indirectly his name was linked to homonymous mysterious hermit protagonist of the "Lezenda" of Raniero Fasani itself. During the experimental campaign, the thermographic acquisitions, in conjunction with digital photography, were executed on the south wall of the nave since the opposite wall and the apse are in aggregate with other parts of the complex of San Bevignate (not the ideal environmental conditions under which passive thermal imaging must be performed), Figure 3. Furthermore, at the time of the surveys, the entrance wall and other areas were covered by scaffoldings, because there was a restoration. Among the aformentioned valuable mural paintings, the only certainly contemporaneous with the Templar period are actually those of the counter-façade and those above the apse, all the others belong therefore to other Orders. More specifically speaking, the series of the Apostles stands out on the side walls superimposed on the previous decorations, Figure 4. With reference to the counter-façade above the main entrance, is observable an unusual iconographic choice arranged in two registers inherent the efforts of the Templars in defence of the holy sepulchre. Referring to the apse, articulated decorative themes are observable portraying Biblical scenes and representations of Templar symbology and of local religious life (e.g., some flagellants can be seen and two effigies of San Bevignate), Figure 5. Concerning the apse and the decorations of the adjacent spans, geometric bands with the cornflower sign refer to the French origin of the Templar order and the presence of the nine stars surrounding the Templar cross in the fresco above the apse itself describes the nine Templars who founded the Order. At the top of the main wall of the apse the Virgin and Child are represented enthroned surrounded by angels; under the windows, there are the symbols of the four Evangelists and in the centre, immediately behind the altar, the Crucifixion is painted. On the left wall of the Last Supper is represented and on the right wall, which has no openings interruptions, the Universal Judgment is portrayed. In these portions, some flagellants can be seen and this testifies the fact that the monks of San Bevignate did not limit themselves to administering the Templar assets, but they also carried out functions of assistance and apostolate among the local inhabitants. At the end of the nave that leads to the apse, above a pointed arch 
and within a complex decorative theme, fragments of the story of a miracle attributed to San Bevignate can be glimpsed, in particular the event in which he revives a child torn to pieces by a wolf. Behind the altar, a portrait of San Bevignate with a halo merits special mention and in this scene, as previous described, he receives the blessing of a bishop who seems to grant him the place in which to erect his church. In conclusion of this section, it behoves to bring up that at the same time as the restoration works following the '97 earthquake, valuable Roman ruins were discovered under the church's floorings. The finds extend for almost the entire width of the nave above and consist in an ancient fullonica characterized by the presence of five basins. The fragment of a mosaic with black and white tesserae, on the other hand, is attributable to a previous Roman domus dating back to around the second half of 1 st century BC. To date, this archaeological site which also includes the crypt where was probably buried the Saint, apart from the church, is completely open to the public in a single museum itinerary.

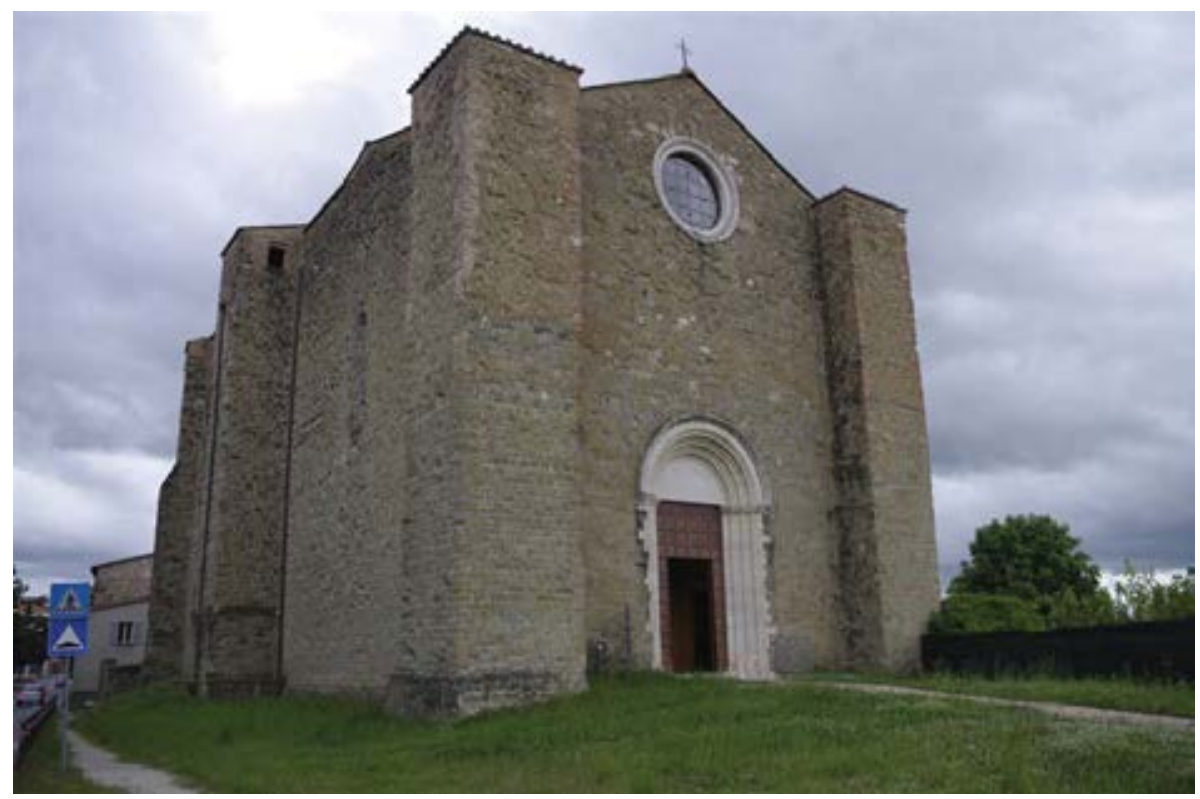

Figure 2: External view of San Bevignate. Image taken from https://www.iluoghidelsilenzio.it/chiesa-di-sanbevignate-perugia/.

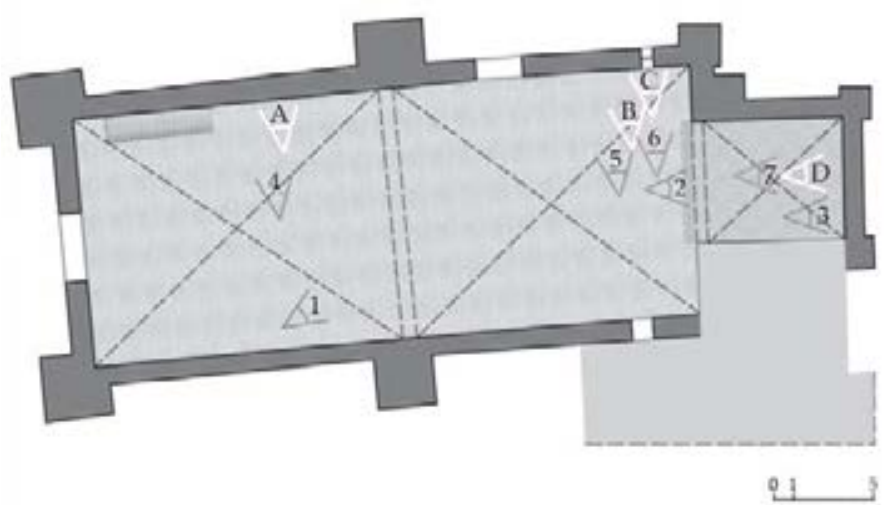

Figure 3: Schematization of the plan of the Church, inside the photographic cones of vision chosen for the survey: in white the settings of thermographic shootings, in grey the digital photography ones. 


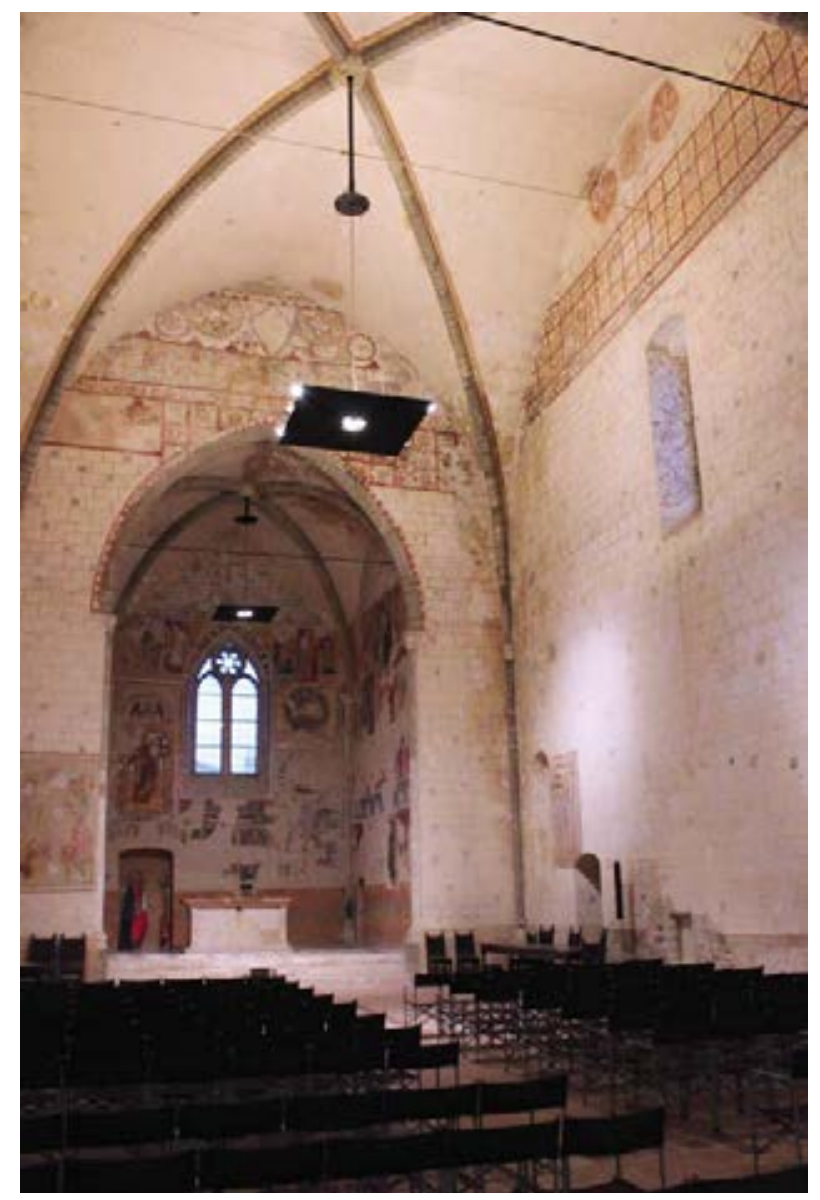

Figure 4: Inner view of the church of San Bevignate (see cone of vision 1 in Figure 3).

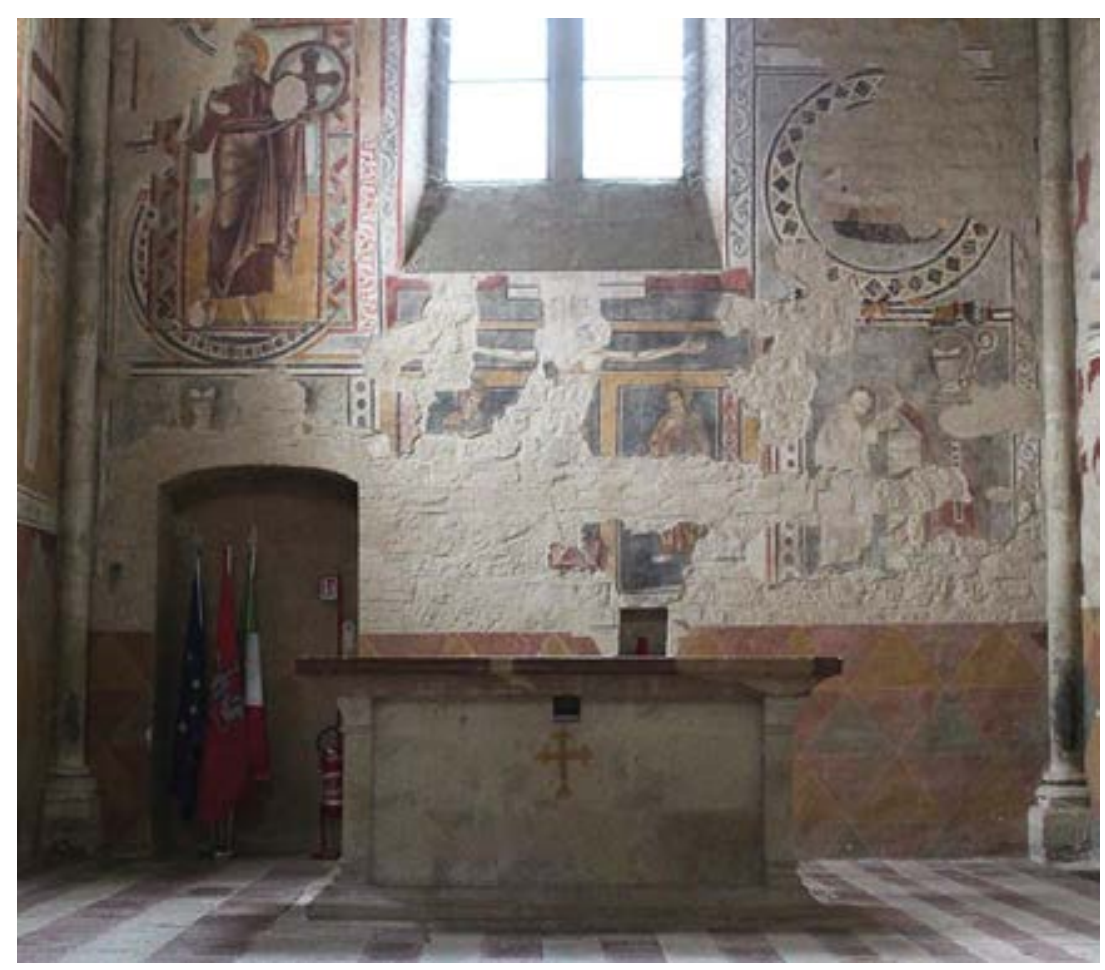

Figure 5: Picture of the altar, in background the lower register of the apse'frescoes (see cone of vision 2 in Figure 3). 


\section{INFLUENCE OF PLASTER THICKNESS}

One of the key factors in assessing the correct texture of the masonry is the plaster thickness. In particular, since the plaster is made of a material which is very similar to the one the joints are made of, and it has usually a greater thermal conductivity than the stone, the plaster diffuses the thermal flux as it crosses the plaster, therefore the thermographic image, which measures the temperature differences on the surface of the wall, may not represent in detail the actual texture but could overestimate the presence of the mortar. In order to clarify this aspect, which is crucial in estimating the mechanical properties of the masonry since usually the mortar is the weaker phase, a preliminary study based on a numerical procedure using thermal finite element analysis has been developed. A masonry wall was realized with bricks having width $250 \mathrm{~mm}$ and height $55 \mathrm{~mm}$, the thickness of the wall was $120 \mathrm{~mm}$. A running bond texture was used, with mortar joints having thickness $10 \mathrm{~mm}$. Several thickness of plaster were considered, from $5 \mathrm{~mm}$ to $15 \mathrm{~mm}$. In Figure 6 the surface temperature read in the outdoor surface of the wall in steady state when the indoor temperature was $20^{\circ} \mathrm{C}$ and the outdoor temperature was $0^{\circ} \mathrm{C}$ is shown. The plaster covers only the outdoor surface of the wall.
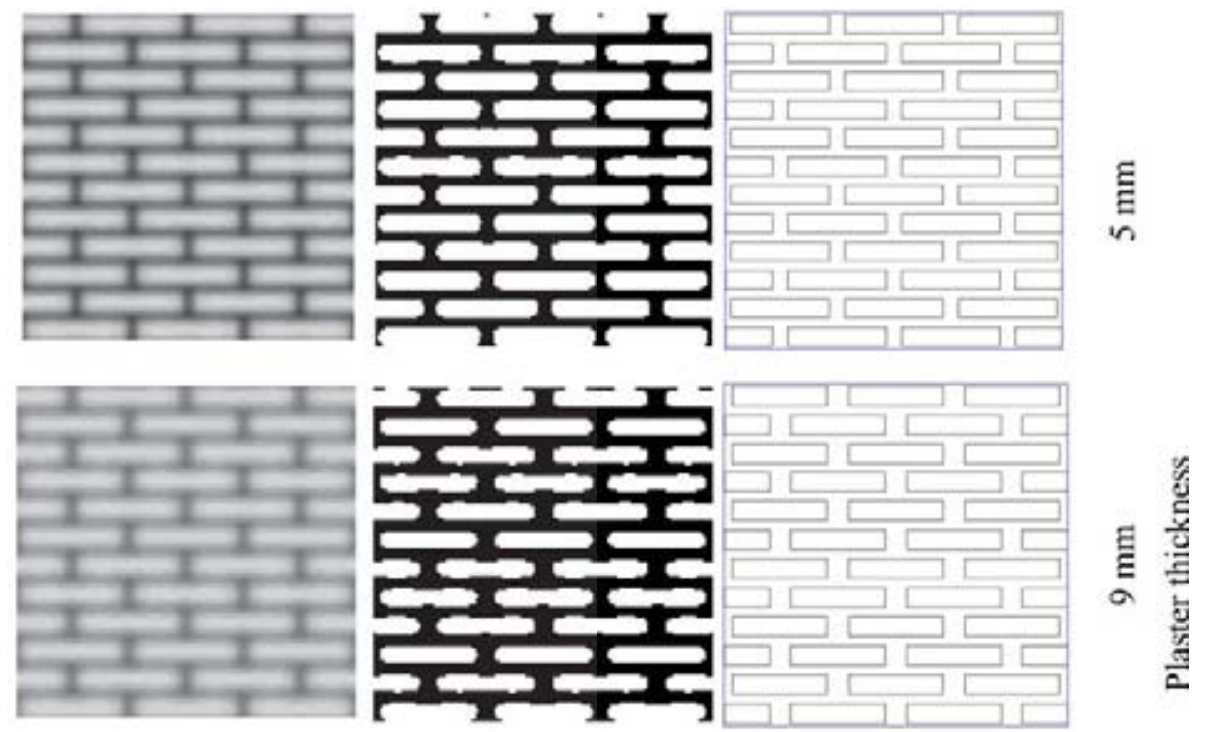

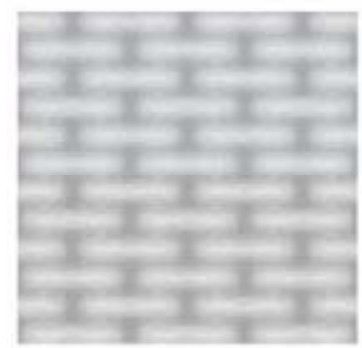

(a)

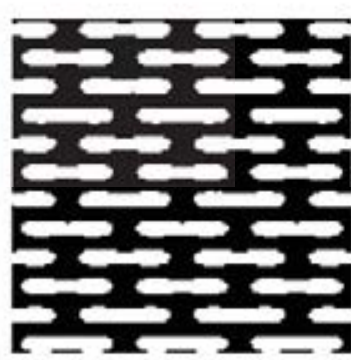

(b)

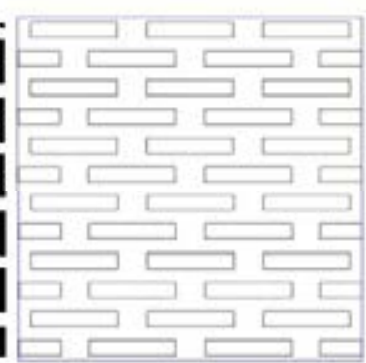

(c)

Figure 6: (a) Simulation of thermal image, (b) binary image, (c) equivalent rectangular blocks.

In the same figure, the black and white binary images obtained are shown. In order to simplify the interpretation of the results, the stones were transformed to equivalent rectangular blocks, as shown in the previous figure.

In Figure 7 the concentration ratio of the stone, which is the strong phase, is shown and compared with the reference value. 


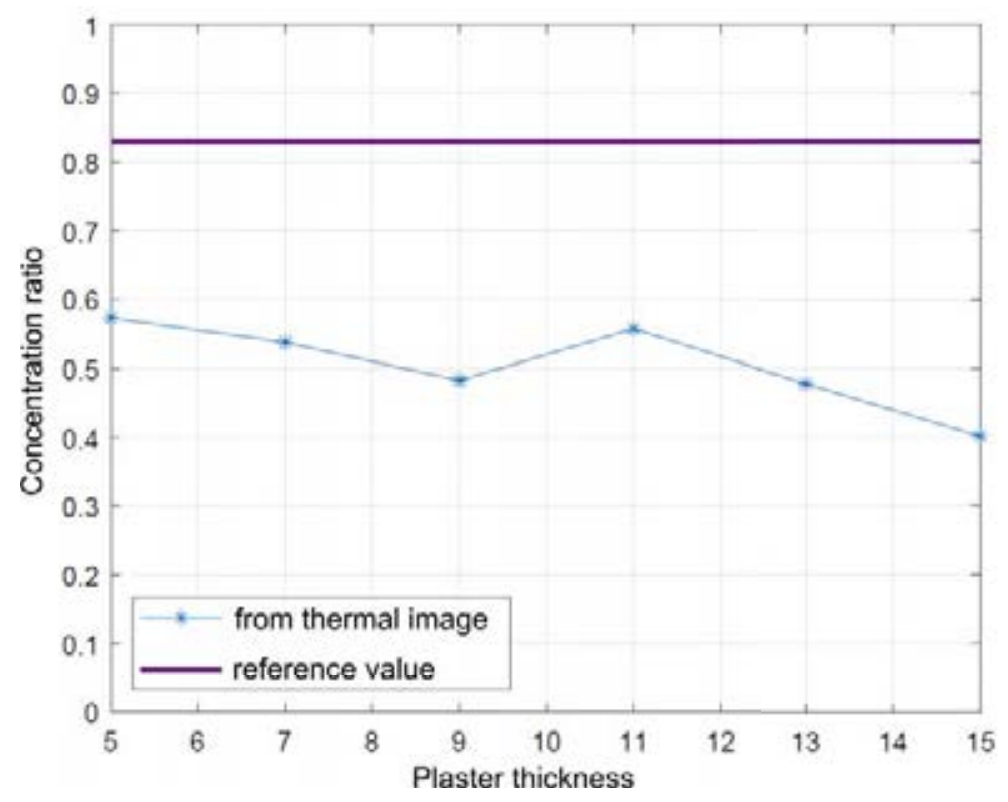

Figure 7: Concentration ratio of strong phase for various plaster thicknesses.

As can be appreciated, it seems that even small values of plaster thickness lead to a quite large decrement of the percentage estimated for the stones, and therefore further studies are necessary in order to fully assess the influence of plaster thickness when estimating the mechanical characteristics of the wall.

\section{EXECUTION OF THE EXPERIMENTAL CAMPAIGN AND DIGITAL IMAGING}

New technologies allow to conduct experimental investigations without harming the architectural quality of constructions, such innovations are exactly fitting with the disciplines inherent the heritage architectures $[14,15]$. Among the important factors influencing the seismic response of Heritage buildings, the masonry quality and the knowledge of its processes of stratification are certainly enclosed. The acquisition of information about the non-visible masonry texture is the subject of such contribution, under the assumption that the masonry quality is the basic element to analyse and eventually improve, e.g. regarding the preferable monolithic behaviour, before to add any reinforcement intervention (metal tie-rods, mortar injections etc.).

During the actual experimental campaign, the experimental measurements were focused on the north frescoed wall of the nave and the thermographic "pictures" were taken under passive conditions: the inner wall's surfaces were analysed without heating them, by exploiting direct sunlight and observing the thermal transient on them. This results in different responses from the elements with different thermal capacity, in particular by identifying - as mentioned earlier - with black pixels the mortar and with the white ones the stone elements.

Referring to the frescoes that decorate the examined wall, rows of overlapping ashlars are reproduced to imitate an austere wall face made of stone, this is a typical decoration of the Templar churches aimed to recall the poverty of the holy land. Moreover, the series of the twelve apostles stand out, distributed also on the other side wall, on the façade and the back walls of the apse; such pictorial cycles were superimposed on the original decoration during a second phase between 1283 and 1285. In particular, a first tranche of thermographic surveys covered the mural paintings concerning the apostle's cycle, Figure 6.

Furthermore, dealing with a real architecture, it was necessary to add to the procedure a new 
phase in order to enhance the quality of the final binary image, which is strictly connected to the sharpness of the starting thermographic image. Indeed, compared to what has been above described, an adjust contrast tool has been used aiming to improve the black-to-white mapping of the thermographic greyscale image. In visual perception, the contrast is the difference in luminance of colours that makes the elements of an image clearly distinguishable within the same field of view. In the light of the above, the thermal images recorded during the surveys were preliminarily modified by adjusting contrast so that the differences between black and white were sharp and the highlights looks brighter and the shadows looks darker, with intensity values that fill the entire range of intensities $[0,255]$. Then, the procedure above described in Section 2, was applied.

\section{MASONRY WALL TEXTURE AND PECULIAR CHARACTERISTICS OF THE FRESCOES}

The approach was to have first an overview of the masonry texture and its quality and then to proceed gradually more and more closely to the wall's faces. Along with the thermographic images ordinary digital photos have been taken; in addition, reference thermal reflective elements have been placed in front of the frescoes, made by two parallel rigid meter-sticks, in order to be able to overlay subsequently the photos with the corresponding thermographic images in the next phase. Considering that in this first case the meter-sticks were separated by $2.70 \mathrm{~m}$, by means of the procedure and its final binary images, elaborated by straightening photographic and measurements digital techniques, it was possible not only to seize the quality of the masonry texture but also its dimensional features, Figures 9 and 10.

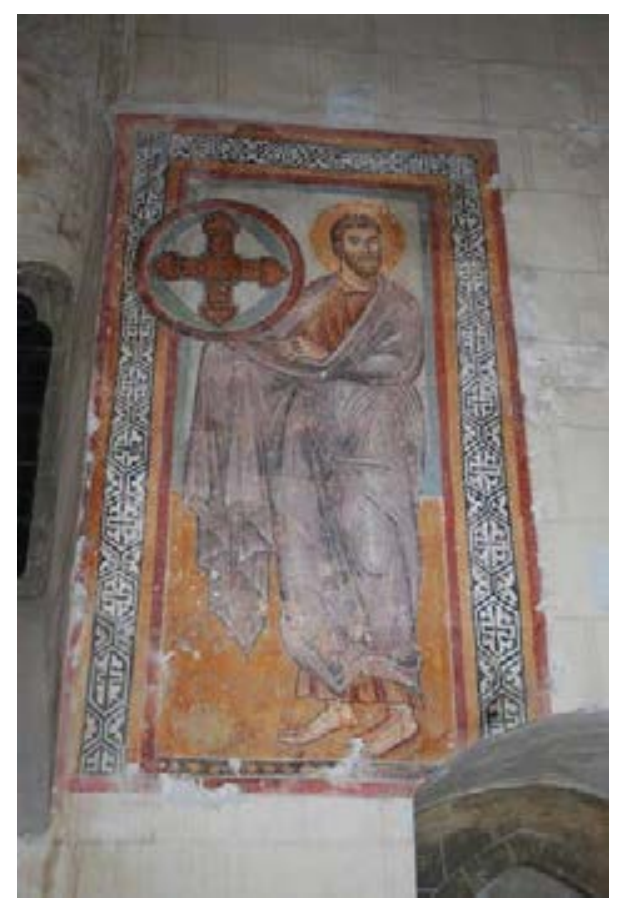

Figure 8: One of the frescoes under investigation, in particular one belonging to the apostle's cycle. 3.

A quasi-periodic texture made of stone blocks with different widths, ranging from 25 to 60 $\mathrm{cm}$, but similar heights, of about $20 \mathrm{~cm}$, has been observed; such results matches with what was surveyed in the apse, concerning the areas where the fresco peeled off (see Figure 5) and on the external façades. 
The benefits offered by the thermal imaging methods, regarding the safeguard of frescoes, mural paintings and valuable architectonic elements, have been addressed by numerous authors $[17,18,19,20,16]$. In addition, it was possible to contextually ascertain that there are no detachments or infiltration phenomena in place that can afflict the health of the frescoes. Moreover, recalling the historical researches from which emerged that the frescoes of the Apostles was superimposed to the pre-existing ones, the mortar distribution (in those areas ) suggests a trace of the ancient techniques of fresco-makers: the surface of the previous fresco had been probably "excavated" by the masons, allowing the new fresh plaster to cling to the ancient mortar below, a less smooth and slippery surface than the one of the wall. Then, the presence of few fragments of mortar out of the joints may show that in order to seat the new murals some holes were made by hands in the previous frescoes and so their orientation does not follow an exact pattern [17]. This, therefore, testifies that the proposed thermographic method, thanks to the possibility to improve the parameters described Section 2, allows to gaininformation, which must be critically analysed, even about masonries subjected to various superimposed layers of frescoes. 


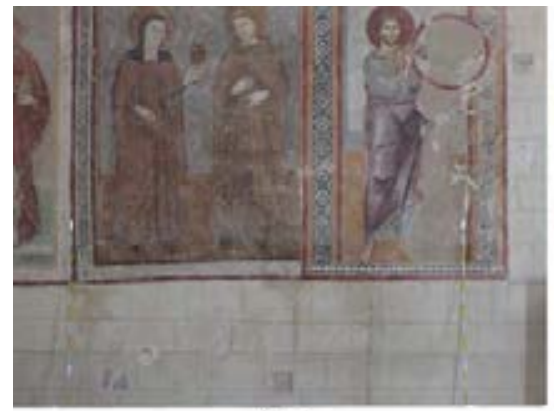

(a)

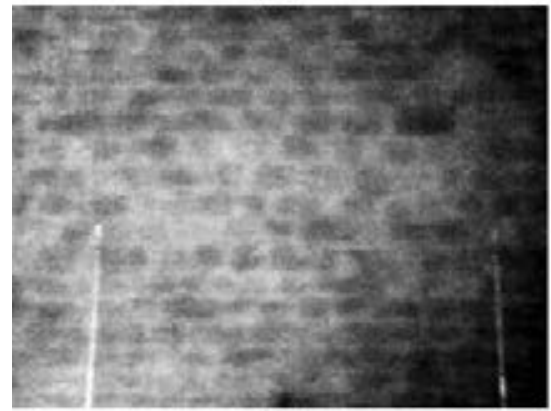

(b)

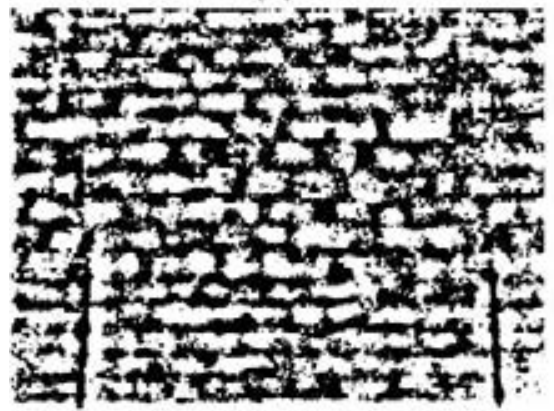

(c)

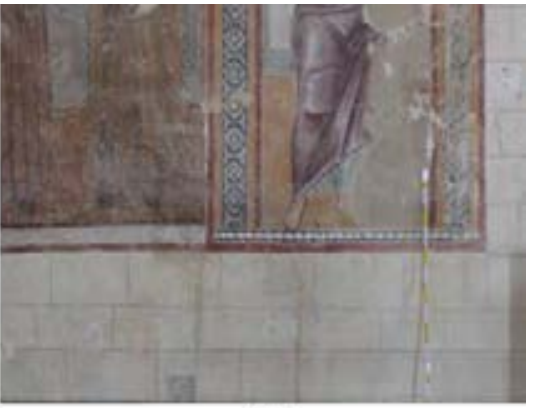

(d)

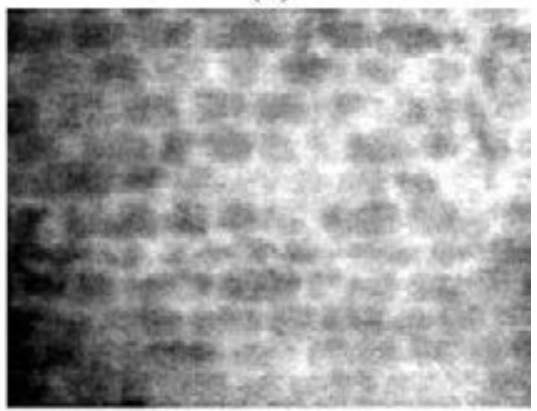

(e)

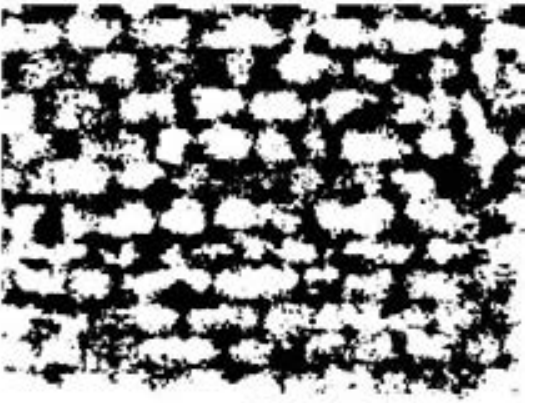

(f)

Figure 9: (a) Fresco under investigation. (b) Thermal image with improved contrast. (c) Final binary image (see the cone of vision A in Figure 3). In the right column, a thermal analysis closer to the masonry surface than the previous one: (d) Portion of the fresco under investigation. (e) Thermal image with improved contrast. (f) Final binary image (see the cone of vision B in Figure 3).

\section{IDENTIFICATION OF DEFICIENCIES AND DISCONTINUITIES}

The role of the latter approach in detection and qualification of deficiencies/discontinuities in the stonework is an important aspect $[21,22,23,24]$. Through the analysis of another part of the same wall, located near the apse and in the proximity of a window, it was possible to discover the presence of a blind opening in the original masonry, which now is totally bricked up (Figure 10). In this second case the meter-sticks were placed at a distance of about $1.40 \mathrm{~m}$ leading to deduce a size of $65 \times 75 \mathrm{~cm}$ for the part walled up with a masonry typology different from sandstone. Additionally, there was pointed out the different emissivity and the presence of an architrave made of another material (possibly wood) of about $15 \mathrm{~cm}$ thick. Moreover, about the constructive phases and criteria, the peculiar workmanship, and the different material were also observable on the abutments of the window. 


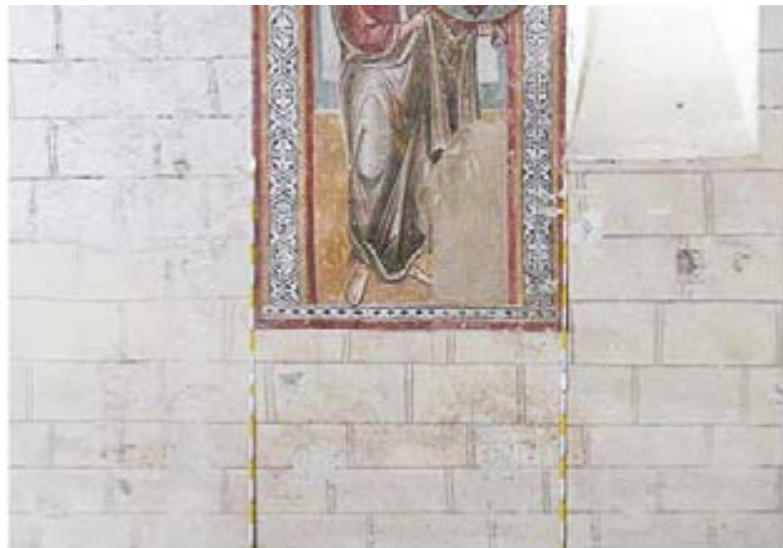

(a)

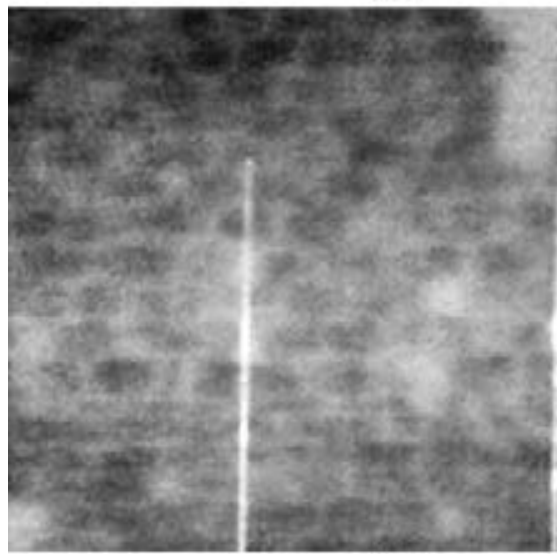

(b)

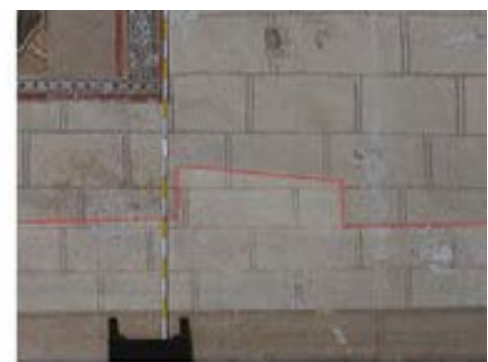

(c)

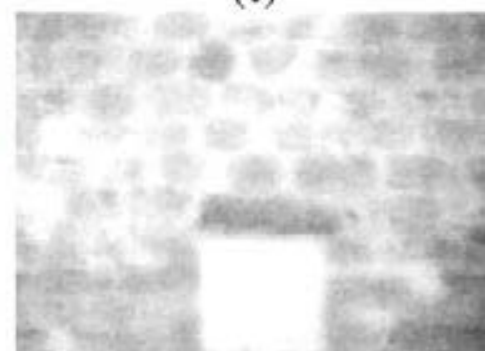

(d)

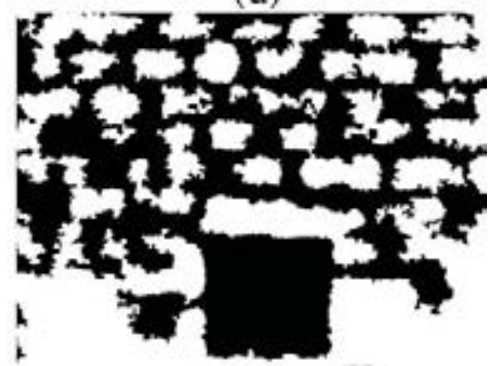

(e)

Figure 10: (a) Picture of a fresco near the apse. In the pictures, the reflective meter-sticks located as reference points for the subsequent post-processing are visible. (b) Thermal image with improved contrast in which are visible the structural peculiarities of the masonry wall, in the right corner is observable the former recess (see the cones of vision 5 and B in Figure 3). (c) Particular of the fresco under investigation, are observable colours of different gradation. (d) Thermal image with improved contrast. (e) Final binary image (see the cones of visions 6 and $\mathrm{C}$ in Figure 3).

Indeed, a toothing masonry has been realized, characterized by the process of leaving alternate stone "teeths" for a better adjoining block or brick wall to be started from. Even nowadays, such technique is used when windows or door openings must be made from an existing wall, by demolition and cutting of masonry, allowing the adjoining wall to develop without having to adjust or cut bricks. It is also noteworthy to notice how, already with the naked eye - can be seen in Figure 10 - portions of the fresco with colours of different gradation are observable, probably due to varied breathability of the materials making up the masonry. This scenario is also confirmed by what emerged from a closer thermographic picture: assuming a stratigraphic interpretation of the wall, arise the construction phases of the ancient site executed by different bricklayers, made by lower rows of a type of stone (which appears darker) probably of superior quality compared to that of the band between the recess and the window where instead the masonry is composed of smaller elements thus making the presence of mortar predominant. Moreover, it is interesting to reamrk that the filling of the recess does not present any masonry texture as if it had been filled entirely with a concretion material. Finally, a thermographic investigation involved a part of the apse wall. This portion of the church was chosen because here can be found the coexistence of portions of plaster with parts of the masonry emerging, beacuse of the detachments of the fresco that in past centuries were witnessed by the restorers. From the 
thermographic images, one of them can be seen in Figure 11, it appears that to date there are no infiltrative nor detachment or disruptive phenomena of interest undermining the safeguard of the decorations under examination.

However, such item will be taken up in the future developments of the research campaign considering also other portions of the church and to a large extent, with reference to the ongoing works of consolidation, profiting from the opportunity to deepen the knowledge about the architecture and frescoes'manufacturing techniques. Moreover, non-destructive testing (NDT) techniques can be used in regard to both evaluation of mechanical properties and for characterization of microstructural features such as grain size, texture, nucleation, defects, deformations, or damages in various contexts, also concerning historical masonries [25, 26, 27]. In particular, the pictures obtained from thermographic surveys can be used to estimate the elastic characteristics of masonry texture, by means of the method of the test-windows [28]; preliminary results are reported in [7].

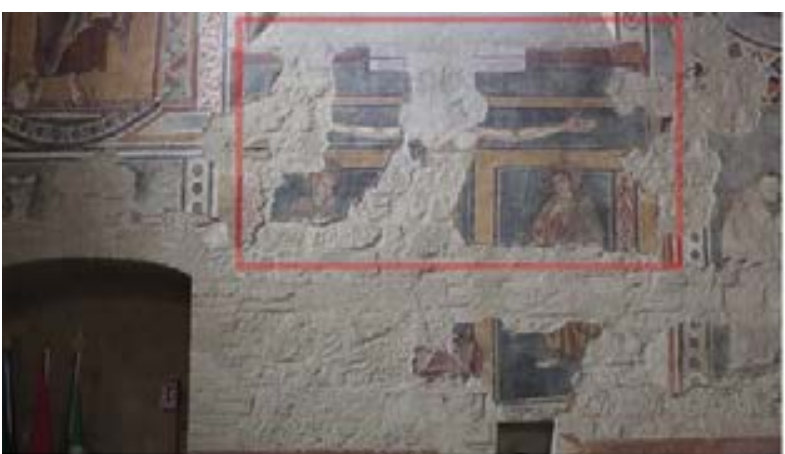

(a)

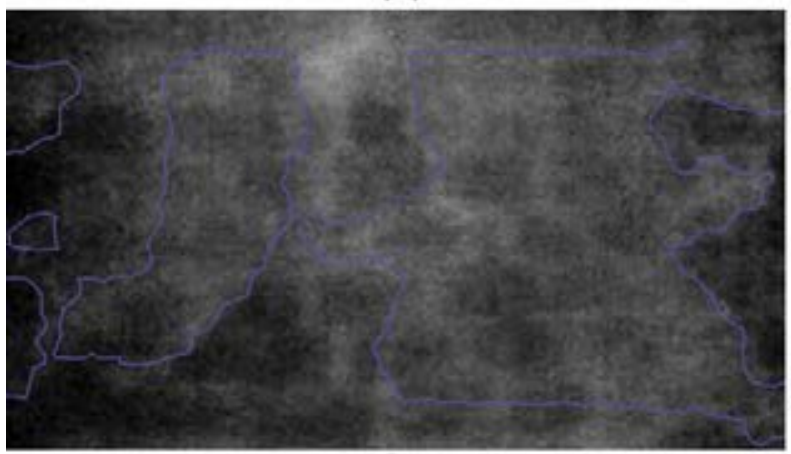

(b)

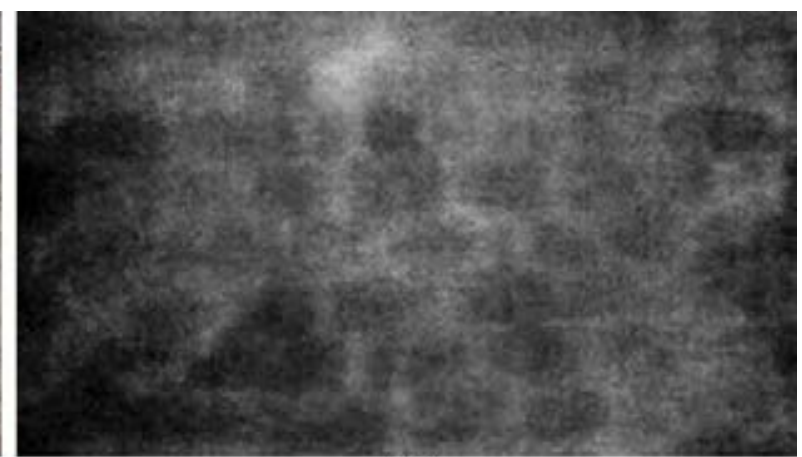

(c)

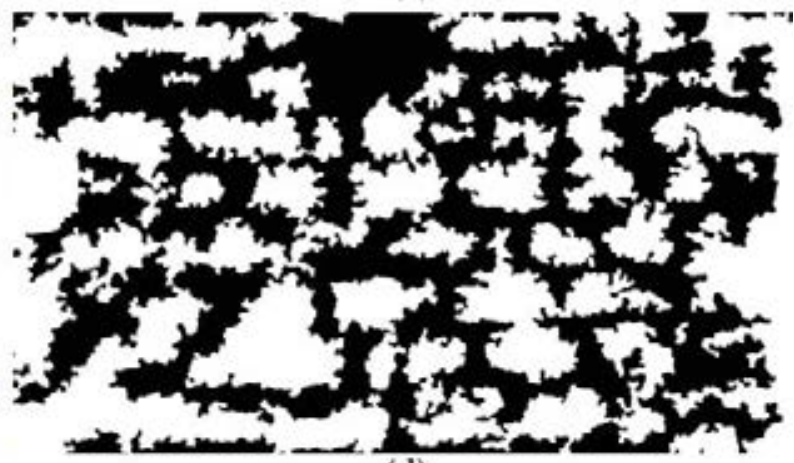

(d)

Figure 11: (a) Portion of the fresco under investigation, (b) thermal image where are highlighted in blue the edges of what remains of the frescoes, (c) thermal image with improved contrast, (d) final binary image (see the cones of vision 7 and D in Figure 3).

\section{CONCLUSIONS}

- A method to identify and interpret the differences of temperature in wall surfaces was proposed and applied to a heritage architecture of great value; enabling the evaluation of the historical masonry texture covered by rare frescoes;

- The outcomes highlighted the reliability of the devised procedures to identify masonry texture, a necessary information to estimate the masonry mechanical characteristics;

- A preliminary study on the influence of plaster thickness has been made; 
- Moreover, the thermographic images have been very useful to detect deficiencies and discontinuities in the wall, besides to find characteristics of the frescoes in terms of realization criteria and actual conservation conditions;

- Without damaging the decorations by taking essays or samples, it was possible to obtain information not only on the risk factors concerning the frescoes conservation but also inherent to the seismic prevention, closely tied to the peculiarities and stratifications of masonry;

- From a future perspective, considering that the results are promising, the thermographic analysis will be extended to other portions of the Church.

\section{Acknowledgements}

This work was supported in part by the Italian Ministry for University and Research (P.R.I.N. National Grant 2017, Project title "Modelling of constitutive laws for traditional and innovative building materials", Project code 2017HFPKZY; University of Perugia Research Unit). This support is gratefully acknowledged. In addition, the authors are grateful to the professional and human endeavour of the Full Professor Paolo Belardi, of the University of Perugia, and to the Dr. Catia Chiaraluce, of the municipality of the city of Perugia, aimed at the creation of a partnership with the local stakeholders. 


\section{REFERENCES}

[1] ICCROM, International Centre for the Study of the Preservation and Restoration of Cultural Property.15 March 2021; accessible on https://www.iccrom.org/news/italyearthquakes-other-casualty-cultural-heritage.

[2] V. Gusella, R. Liberotti, Seismic Vulnerability of Sub-Structures: Vantitelli's Modulus in Murena Palace. Buildings, 10(9), 164, 2020.

[3] R. Liberotti, F. Cluni, V. Gusella, Vulnerability and seismic improvement of architectural heritage: The case of Palazzo Murena. Earthquakes and Structures, 18(3), 321-335, 2020.

[4] F. Cluni, D. Costarelli, A.M. Minotti, G. Vinti, Enhancement of thermographic images as tool for structural analysis in earthquake engineering. NDT E Int., 60, 60-72, 2015.

[5] F. Cluni, V. Gusella, G. Vinti, Masonry elastic characteristics assessment by thermographic images. Meccanica, 54, 1339-1349, 2019.

[6] F. Cluni, D. Costarelli, V. Gusella, G. Vinti, Reliability increase of masonry characteristics estimation by a sampling algorithm applied to thermographic digital images. Probabilistic Eng. Mech., 60, 2020, 103022, ISSN 0266-8920, https://doi.org/10.1016/j.probengmech.2020.103022.

[7] V. Gusella, F. Cluni, R. Liberotti, Feasibility of a Thermography Nondestructive Technique for Determining the Quality of Historical Frescoed Masonries: Applications on the Templar Church of San Bevignate. Appl. Sci., 11, 281, 2021. https://doi.org/10.3390/app11010281

[8] V. Gusella, F. Cluni, Random field and homogenization for masonry with nonperiodic microstructure. J. Mech. Mater. Struct., 1, 357-386, 2006.

[9] N. Cavalagli, F. Cluni, V. Gusella, Strength domain of non-periodic masonry by homogenization in generalized plane state. Eur. J. Mech.-A/Solids, 30, 113-126, 2011.

[10] F. Gusella, F. Cluni, V. Gusella, Homogenization of dynamic behaviour of heterogeneous beams with random Young's modulus. Eur. J. Mech.-A/Solids, 63, 260-267, 2019.

[11] F. Gusella, F. Cluni, V. Gusella, Homogenization of the heterogeneous beam dynamics: The influence of the random Young's modulus mixing law. Compos. Part B Eng., 167, 608-614, 2019.

[12] U. Nicolini, Le canonizzazioni "facili" del comune di Perugia: Il caso di San Bevignate, già in Templari e Ospitalieri. M. Roncetti, P. Scarpellini, F. Tommasi, F. eds. Italia. La Chiesa di San Bevignate a Perugia, Milano, Italy, 1987, 39-45 (now In IDEM, Scritti di storia; pp. 337-348).

[13] S. Merli, L'insediamento dei Templari a Perugia: da San Giustino d'Arna a San Bevignate. S. Sammarco, S., ed. Commilitones Christi. Miscellanea di studi; Roma, Lisanti, 9-84, 2017. 
[14] E.B. Groth, T.G.R. Clarke, G. Schumacher da Silva, I. Iturrioz, G. Lacidogna, The Elastic Wave Propagation in Rectangular Waveguide Structure: Determination of Dispersion Curves and Their Application in Nondestructive Techniques. Appl. Sci., 10, 4401, 2020.

[15] A. Moropoulou, N.P. Avdelidis, M. Karoglou, E.T. Delegou, E. Alexakis, V. Keramidas, Multispectral Applications of Infrared Thermography in the Diagnosis and Protection of Built Cultural Heritage. Appl. Sci., 8, 284, 2018.

[16] , E. Verstrynge, G. Lacidogna, F. Accornero, A. Tomor, A review on acoustic emission monitoring for damage detection in masonry structures. Constr. Build. Mater, 121089, 2020, ISSN 0950-0618, https://doi.org/10.1016/j.conbuildmat.2020.121089.

[17] G. Botticelli, Metodologia di Restauro delle Pitture Murali. Ediz. Ampliata. StreetLib, Florence, Italy, 2020.

[18] E.Z. Kordatos, D.A. Exarchos, C. Stavrakos, A. Moropoulou, T.E. Matikas, Infrared thermographic inspection of murals and characterization of degradation in historic monuments. Constr. Build. Mater., 48, 1261-1265, 2013.

[19] N. Lermé, S. Le Hégarat-Mascle, B. Zhang, E. Aldea, Fast and efficient reconstruction of digitized frescoes. Pattern Recognit. Lett., 138, 417-423, 2020.

[20] G.M. Carlomagno, C. Meola, Comparison between thermographic techniques for frescoes NDT. NDT E Int., 35, 559-565, 2002.

[21] S. Sfarra, S. Laureti, G. Gargiulo, H. Malekmohammadi,M.A. Sangiovanni, M. La Russa, P. Burrascano, M. Ricci, Low Thermal Conductivity Materials and Very Low Heat Power: A Demanding Challenge in the Detection of Flaws in Multi-Layer Wooden Cultural Heritage Objects Solved by Pulse-Compression Thermography Technique. Appl. Sci. , 10, 4223, 2020.

[22] F. Mercuri, N. Orazi, S. Paoloni, C. Cicero, U. Zammit, Pulsed Thermography Applied to the Study of Cultural Heritage. Appl. Sci., 7, 1010, 2017.

[23] C. Lerma, Á. Mas, E. Gil, J. Vercher, Hygrothermal Behaviour of Continuous Air Chambers on Stone Panels Façades through CFD and IRT. Appl. Sci., 9, 3001, 2019.

[24] I. Campione, F. Lucchi, N. Santopuoli, L. Seccia, 3D Thermal Imaging System with Decoupled Acquisition for Industrial and Cultural Heritage Applications. Appl. Sci., 10, $828,2020$.

[25] G. Vasconcelos, P. Lourenço, C. Alves, J. Pamplona, Ultrasonic evaluation of the physical and mechanical properties of granites. Ultrasonics, 48, 453-466, 2008.

[26] S. Noor-E-Khuda, F. Albermani, Mechanical properties of clay masonry units: Destructive and ultrasonic testing. Constr. Build. Mater., 219, 111-120, 2020.

[27] E. Vasanelli, A. Calia, D. Colangiuli, F. Micelli, M.A. Aiello, Assessing the reliability of non-destructive and moderately invasive techniques for the evaluation of uniaxial compressive strength of stone masonry units. Constr. Build. Mater., 124, 575-581, 2016.

[28] F. Cluni, V. Gusella, Homogenization of non-periodic masonry structures. Int. J. Solids Struct., 41, 1911-1923, 2004. 